\title{
Cisto epidermóide: relato de caso ${ }^{1}$
}

Renato Lamounier Barbieri

Uninove. São Paulo - SP [Brasil]

renatolb@uninove.br

Alexandre Hideo Kajita

Graduando em Medicina - Uninove.

São Paulo - SP [Brasil]

avakajita@uol.com.br

Gabriela Matielo Galli

Graduanda em Medicina - Uninove.

São Paulo - SP [Brasil]

gabimatielo@hotmail.com

Karyne Flório Mediotti

Graduanda em Medicina - Uninove.

São Paulo - SP [Brasil]

kmediotti@uol.com.br

Paulo Augusto Cozar Figueiredo

Graduando em Medicina - Uninove.

São Paulo - SP [Brasil]

gutocozar@gmail.com

Thiago Martins Fontes

Graduando em Medicina - Uninove.

São Paulo - SP [Brasil]

thifontes2003@yahoo.com.br

Suely de Fátima Parreira

Uninove. São Paulo - SP [Brasil]

sfparreira@uninove.br

Os cistos epidermóides, também denominados cistos cutâneos, são tumores muito freqüentes, que podem requerer cuidados cirúrgicos. Na maioria das vezes, em razão da apresentação clínica patognomônica e de curso indolente, são simplesmente removidos. Habitualmente, o diagnóstico clínico é de fácil confirmação na cirurgia devido ao aspecto típico de formação cística preenchida com um fluido cremoso. Comumente tais lesões "típicas" não sofrem investigação histológica após a remoção. Entretanto, este relato de caso de um cisto epidérmico em couro cabeludo vai mais além, produzindo, por meio de técnicas laboratoriais de rotina, uma análise histopatológica, que revelou a existência de um cisto típico, esférico e esbranquiçado, preenchido, predominantemente, por lâminas de queratina, delimitado por um epitélio estratificado e envolvido por uma cápsula de tecido conjuntivo denso modelado.

Palavras-chave: Cisto. Cisto epidérmico. Histologia. Histopatologia. 


\section{Introdução e relato do caso}

Um cisto é um espaço revestido por epitélio, e seu conteúdo, geralmente, é produto de seu revestimento, o qual não apresenta relação vascular com a parede (WOLKOFF, 2005; GUIMARÃES, 2002). Alguns cistos são de inclusão ou retenção de estruturas normais (como cistos relacionados ao folículo piloso) (ELDER et al., 2001). Cistos epidérmicos são tumores de natureza benigna, de crescimento lento, elevados, redondos, firmes, intradérmicos ou subcutâneos, que param de crescer após atingirem de 1 a 5 centímetros $(\mathrm{cm})$ de diâmetro, sendo, normalmente, assintomáticos (ROBBINS; CITRAN; KUMAR, 1991; ELDER et al., 2001; VANDEWEYER; RENARD, 2003; BIKMAZ et al., 2005; KALGUTKAR et al., 2006). O termo cisto sebáceo era usado para cistos pilares (ou cistos triquilemais, ou cistos pilosos). Atualmente, os principais cistos cutâneos são os epidérmicos (ou de inclusão epidérmica) e os pilares (SAMPAIO; CASTRO; RIVITTI, 1989; ARNOLD; ODOM; JAMES, 1994; SITTART; PIRES, 1997; BORK; BRÄUNINGER， 1998; SAMPAIO; RIVITTI, 2001).

A maioria dos cistos epidérmicos surge, espontaneamente, nas áreas em que há pêlos, mais comumente na face, no couro cabeludo, no pescoço e no tronco e, ocasionalmente, nas palmas das mãos e nas plantas dos pés, e, às vezes, como resultado de um traumatismo (LEVER; SCHAUMBURG-LEVER, 1991). Os cistos do tipo epidérmico são provenientes da ectopia do epitélio e apresentam aparência perolada; os do tipo glandular correspondem à obstrução de um ducto glandular excretor seroso ou mucoso (STEFFEN, 1995). A World Health Organization (WHO) classifica esse tipo de cisto como um tumor associado aos folículos pilosos (HEENAN; ELDER; SOBIN, 1996) e que está intimamente relacionado ao cisto infundibular, definido como um nódulo cístico da derme delimitado por um epitélio estratificado "pavimentoso" e por uma camada granular contendo lâminas de queratina (HEENAN; ELDER; SOBIN, 1996). O aspecto macroscópico e a textura do conteúdo dos cistos epidérmicos variam de acordo com o caso e podem ser acinzentados, moles e de baixa densidade, brancos, firmes e compactos (HATTORI, 2004).

Os cistos epidérmicos têm parede composta de epiderme verdadeira e podem ser vistos na superfície da pele e no infundíbulo de folículos pilosos (Vale lembrar que o infundíbulo, nesse caso, constitui a parte superior do folículo piloso, que se estende para baixo até a entrada do ducto sebáceo) (ELDER et al., 2001). Histopatologicamente, eles sempre contêm queratina em lâminas, diferindo apenas em densidade e compactação (HATTORI, 2004). Nos cistos epidérmicos jovens, coexistem diversas camadas de células pavimentosas e granulosas, geralmente evidentes. Nos epidérmicos mais crônicos, a parede é, por vezes, atrófica, e pode constituir-se de uma ou duas fileiras de células significativamente achatadas. O cisto é preenchido com material córneo, disposto em camadas laminadas. Em caso de rompimento de um cisto epidérmico, o conteúdo é liberado para a região dérmica, o que provoca uma reação de corpo estranho, em que numerosas células gigantes multinucleadas formam um granuloma de queratina. Esse processo provoca uma desintegração da parede do cisto e pode levar também a uma proliferação pseudo-epiteliomatosa em resíduos dessa parede, simulando um carcinoma de células pavimentosas (ANDERSON; KISSANE, 1982; ROBBINS; CITRAN; KUMAR, 1991; ELDER et al., 2001).

Como manifestação clínica, as lesões são esféricas, geralmente móveis, indolores, de consistência elástica ou endurecida. Podem variar de pequenos cistos (menores de $1 \mathrm{~cm}$ ) a lesões com vários centímetros (SITTART; PIRES, 1997). A cabeça, o pescoço e o tronco são as regiões mais afetadas, podendo haver um ponto central, escuro, da abertura de um folículo piloso (ROUQUAYROL; ALMEIDA FILHO, 1999). Os cistos são assintomáticos e, se estiverem localizados nas extremidades ósseas do tronco ou no couro cabeludo, podem causar incômodo ao de- 
cúbito ou à compressão. Em caso de inflamação secundária por ruptura da cápsula e/ou infecção, os cistos tornam-se avermelhados, quentes e dolorosos (SAMPAIO; CASTRO; RIVVITTI, 1989; SAMPAIO; RIVITTI, 2001).

A conduta para remoção de cistos é cirúrgica. Dependendo do tamanho, do tipo e da localização da lesão, embora se possa fazer a drenagem do conteúdo do cisto ou destruir a cápsula com cáusticos, preconiza-se a excisão completa de ambos, podendo haver sutura. A não-excisão completa do cisto pode acarretar um quadro de recidiva da lesão (WYNGAARDEN; SMITH, 1990; MURPHY; ELDER, 1991; SITTART; PIRES, 1997).

Neste estudo, examinamos o caso de R. L. B., 47 anos, sexo masculino, natural e procedente de São Paulo (SP) - brasileiro, branco, biólogo, anglicano. Há cerca de três anos, notou o surgimento de nódulo denso na região cefálica posterior em face parietal esquerda, com crescimento lento e apresentando cerca de $1 \mathrm{~cm}$ de diâmetro ao exame físico, não referindo antecedentes patológicos relacionados ao quadro atual. Negava dor, calor, confirmando tumor, e “... o incômodo ao toque pela sensação da protuberância..." (sic).

\section{Histopatologia}

A cirurgia dermatológica para a excisão de cisto epidérmico é um procedimento seguro, pequeno e rápido, podendo ser realizado, na maioria dos casos, fora de ambiente hospitalar, com plena segurança.

Inicia-se com a remoção pilosa local, caso esteja presente, assepsia local, anestesia injetável local ou tópica. A incisão é feita com lâmina fria, em aspecto fusiforme, e segue as linhas de tensão, até remover-se a lesão por completo. Dependendo do grau de comprometimento dérmico, pode haver a exérese completa da pele. Na síntese da ferida cirúrgica, faz-se a sutura simples, utilizando-se pontos internos ou externos, reabsorvíveis ou não. Os pontos externos são retirados em 5 a 15 dias, dependendo da cicatrização local.

Após a sua excisão, o cisto foi imerso em solução fixadora de Bouin (BEHMER; TOLOSA; FREITAS NETO, 1976) e a amostra conduzida ao Laboratório de Pesquisa da Uninove (Unidade Vergueiro), para a continuidade do processamento do material.

Processou-se a amostra de acordo com as técnicas de rotina histológica, com sua desidratação em crescentes concentrações alcoólicas (álcool $70^{\circ}$ ao álcool absoluto), diafanização em xilol, infiltração e inclusão em parafina histológica. Posteriormente, foram feitos cortes histológicos de 4 micrômetros ( $\mu \mathrm{m}$ ) de espessura em micrótomo automático Leica RM 2125 NT, com navalha de aço, e levados a um recipiente contendo água destilada (35 graus Celsius $\left.\left[{ }^{\circ} \mathrm{C}\right]\right)$ para serem colhidos em lâminas de vidro. Depois de desparafinados em estufa a $60^{\circ} \mathrm{C}$ overnight, foram hidratados em soluções alcoólicas decrescentes e corados pelo método da hematoxilina e eosina (HE) e pela histoquímica do ácido periódico de Schiff (PAS). Em uma nova etapa, foram novamente desidratados, diafanizados e montados com lamínula aderida à lâmina com bálsamo do Canadá.

Os preparados histológicos tiveram suas imagens capturadas e digitalizadas em fotomicroscópio Zeiss Axioskop 2 acoplado à câmera digitalizadora Pixera, conectada ao microcomputador do Laboratório de Endocrinologia de Peixes do Departamento de Biologia Tecidual e do Desenvolvimento do Instituto de Ciências Biomédicas da Universidade de São Paulo (ICB-USP).

Na observação macroscópica, o cisto epidérmico excisado apresentou formato esférico, coloração esbranquiçada, alta densidade ao toque e diâmetro de $0,8 \mathrm{~cm}$.

A análise histopatológica de corte mediano (Ilustração 1) revelou a presença de uma fina cápsula envoltória de tecido conjuntivo denso modelado (Ilustração 2), limitando a camada basal de um epitélio estratificado pavimentoso (Ilustração 3) sem atipias e com larga fai- 
xa interna formada por lâminas de queratina (Ilustração 4). A lesão foi preenchida com material córneo em disposição lamelar, não tendo sido encontrados componentes de anexos cutâneos na lesão (Ilustração 5).

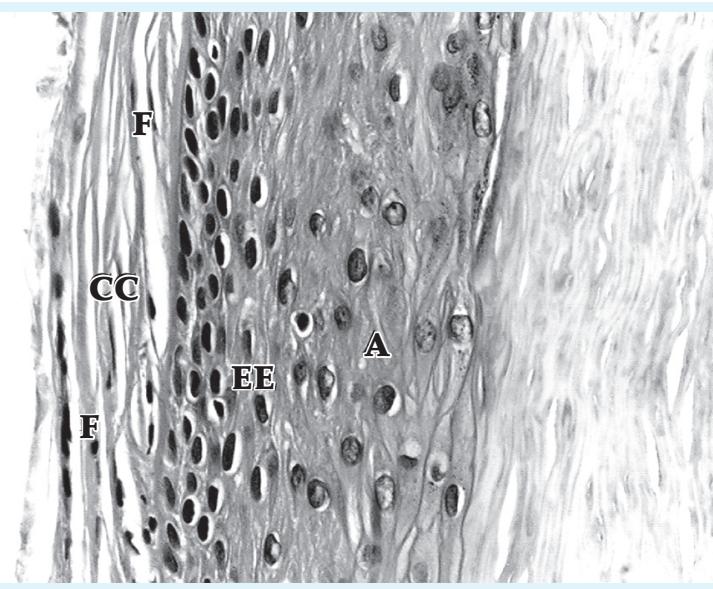

Ilustração 1: A cóppsula conjuntiva (CC) envoltória apresenta os núcleos dos fibrócitos (F) dispostos no mesmo sentido de orientação que as fibras colágenas. A porção basal do estratificado (EE) indica uma grande densidade populacional de células. As células mais apicais $(A)$ possuem maior conteúdo citoplasmático. HE (20 vezes)

Fonte: Os autores

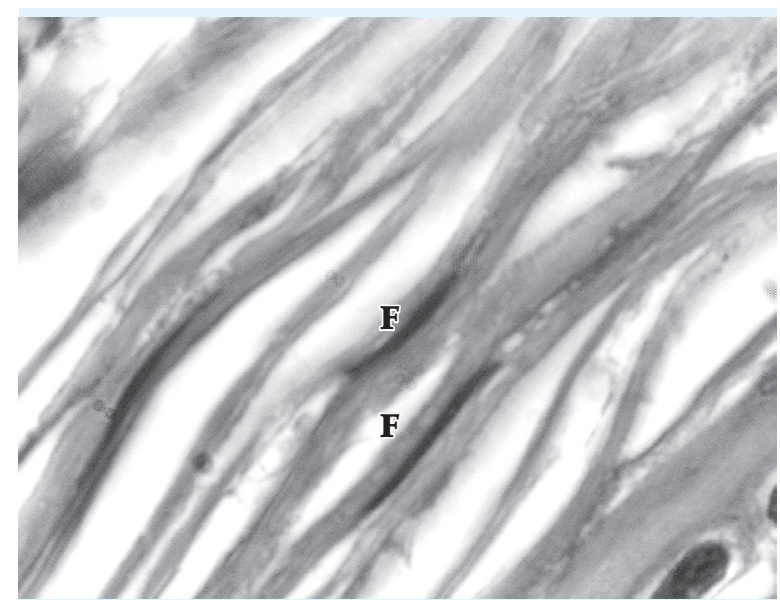

Ilustração 2: Cópsula envoltória de tecido conjuntivo denso modelado, com núcleos dos fibrócitos (F) em evidente concordância com o sentido de direção das fibras colágenas. HE (100 vezes)

Fonte: Os autores

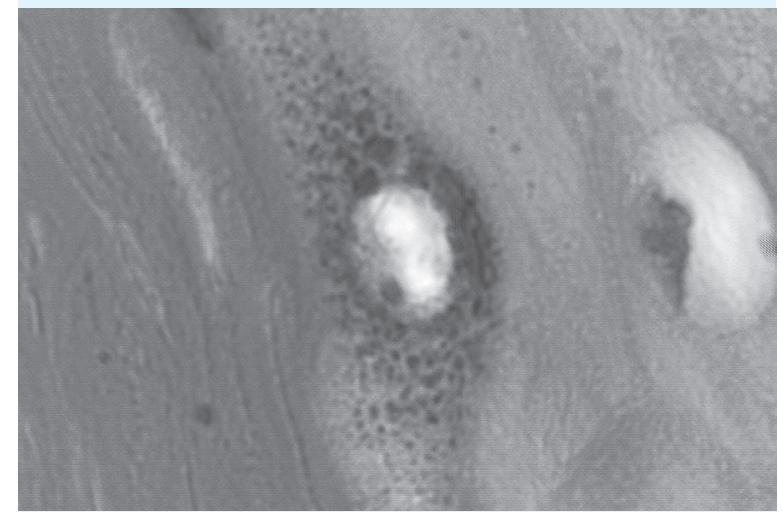

Ilustração 3: Célula da camada granulosa (ao centro) apresentando citoplasma rico em grânulos de querato-hialaina. HE (100 vezes) Fonte: Os autores

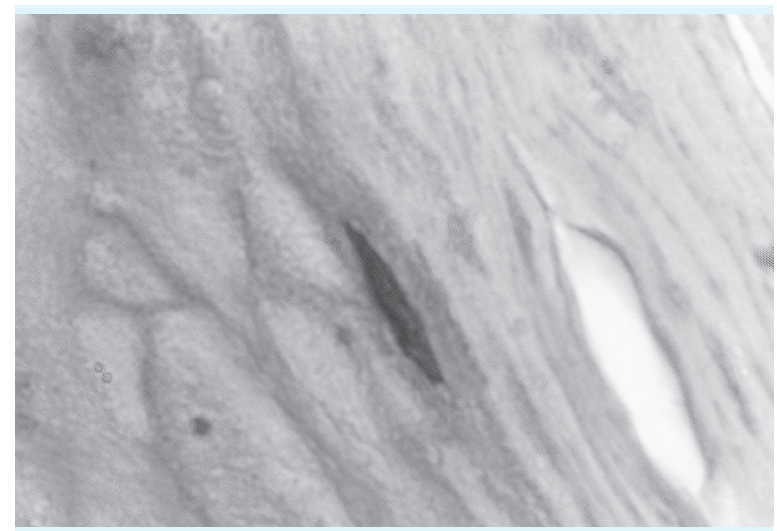

Ilustração 4: Célula pavimentosa com núcleo evidente (ao centro) do estado lúcido. HE (100 vezes)

Fonte: Os autores

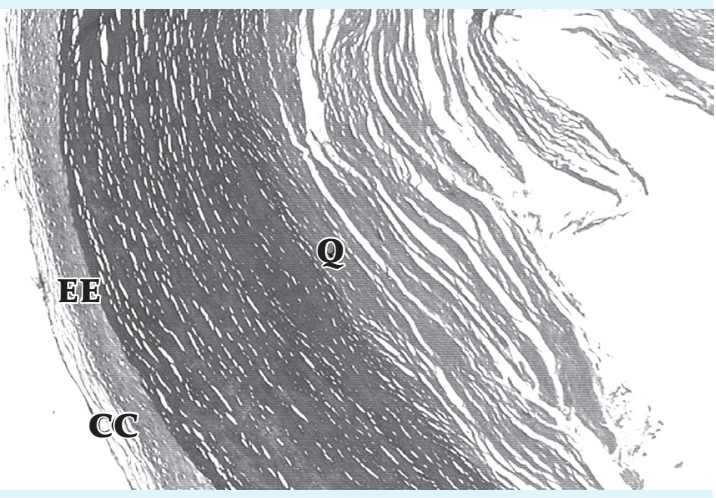

Ilustração 5: O conteúdo do cisto era predominantemente formado por lâminas de queratina (Q), apoiadas sobre um epitélio estratificado (EE) e com uma cápsula conjuntiva envoltória (CC). HE ( 2,5 vezes)

Fonte: Os autores 


\section{Considerações finais}

O cisto epidérmico, freqüentemente encontrado no tecido subcutâneo, constitui uma entidade clínica bastante comum e de fácil resolução, apesar de necessitar de uma conduta cirúrgica. Entretanto requer uma precisão acurada, pois qualquer lesão no cisto extirpado que permita o extravasamento do seu conteúdo na ferida cirúrgica pode tornar o processo recidivante, figurando como um quadro iatrogênico. O cisto epidérmico analisado não apresentou diferenças morfológicas em relação aos que se encontram descritos na literatura disponível nem as características histológicas representantes de anexos cutâneos, como folículos pilosos e glândulas sebáceas e sudoríparas. O paciente, até a edição deste relato de caso, não havia apresentado recidiva do quadro inicial.

\section{Epidermal cyst: a case review}

Epidermal cysts, also named cutaneous cysts, are extremely frequent tumors that would need surgical attention. Mostly, due to their quite pathognomonic clinical presentation and indolent course, they are simply enucleated. Usually the clinical diagnosis is easily confirmed at surgery by the typical appearance of a cystic formation filled with a creamy fluid. It is frequent for such "typical" lesions to escape from histological investigation following removal. However, this case report of an epidermal cyst on the scalp goes beyond, producing a histopathological analysis by laboratorial routine techniques that revealed a typical white rounded cyst, filled by keratin sheet, lined by a squamous stratified epithelium and surrounded by a dense regular connective tissue capsule.

Key words: Cyst. Epidermal cyst. Histology. Histopathology.

\section{Notas}

1 Os autores agradecem ao técnico histologista Cruz Alberto Mendoza Rigonati, do Departamento de Biologia Celular e do
Desenvolvimento, do Instituto de Ciências Biomédicas da Universidade de São Paulo (ICBUSP), pelo valoroso auxílio nas reações histoquímicas; à professora Maria Inês Borella, também do ICB-USP, pelas facilidades concedidas em seu laboratório.

\section{Referênciass}

ANDERSON, W. A. D.; KISSANE, J. M. Patologia. 7. ed. Rio de Janeiro: Guanabara Koogan, 1982.

ARNOLD, H. L.; ODOM, R. B.; JAMES, W. D. Doença de pele de Andrews. Dermatologia clínica. 8. ed. São Paulo: Manole, 1994.

BEHMER, O. A.; TOLOSA, E. M. C.; FREITAS NETO, A. G. Manual de técnicas para histologia normal e patológica. 1. ed. São Paulo: Edusp, 1976.

BIKMAZ, K. et al. Intradiploic epidermoid cysts of the skull: a report of four cases. Clinical Neurology and Neurosurgery, Amsterdã, v. 107, n. 3, p. 262-267, 2005.

BORK, K.; BRÄUNINGER, W. Dermatologia clínica: diagnóstico e terapia. 2. ed. São Paulo: Manole, 1998.

ELDER, J. T. et al. The genetics of psoriasis 2001: the odyssey continues. Archives of Dermatology, Chicago, v. 137, n. 11, p. 1.447-1.454, 2001.

GUIMARÃES, D. T. (Org.). Dicionário de termos médicos e de enfermagem. 1. ed. São Paulo: Rideel, 2002.

HATTORI, H. Epidermal cyst containing numerous spherules of keratin. The British Journal of Dermatology, Oxford, v. 151, n. 6, p. 1286-1287, 2004.

HEENAN, p. J.; ELDER, D. E.; SOBIN, L. H. Histological Typing of Skin Tumors. 2. ed. Berlim: Springer-Verlag, 1996.

KALGUTKAR, A. et al. Intradiploic primary epithelial inclusion cyst of the skull. Annals of Diagnostic Pathology, Filadélfia, v. 10, n. 1, p. 20-23, 2006.

LEVER, W. F.; SCHAUMBURG-LEVER, G. Histopatologia da pele. 7. ed. São Paulo: Manole, 1991.

MURPHY, G. F.; ELDER, D. E. Atlas of tumor pathology.

3. ed. Washington: Armed Forces Institute of Pathology, 1991.

ROBBINS, S. L.; CITRAN, R. S.; KUMAR, V. Robbins: patologia estrutural e funcional. 4. ed. Rio de Janeiro: Guanabara Koogan, 1991. 
ROUQUAYROL, M. Z.; ALMEIDA FILHO, N. Epidemiologia e saúde. 5. ed. Rio de Janeiro: Medsi, 1999.

SAMPAIO, S. A. P.; RIVITTI, E. A. Dermatologia. 2. ed. São Paulo: Artes Médicas; 2001.

SAMPAIO, S. A. P; CASTRO, R. M.; RIVITTI, E. A.

Dermatologia básica. 3. ed. São Paulo: Artes Médicas; 1989.

SITTART, J. A. S.; PIRES, M. C. Dermatologia para o clínico. 1. ed. São Paulo: Lemos Editorial e Gráficos; 1997.

STEFFEN, N. Cistos de pregas vocais: análise de 96 casos. Revista Brasileira de Otorrinolaringologia, São Paulo, v. 61, p. 179-186, 1995. Disponível em: <http://www.rborl.org. br/conteudo/acervo/acervo.asp?id=2060 $>$. Acesso em: 4 dez. 2006.
VANDEWEYER, E.; RENARD, N. Cutaneous cysts: a plea for systematic analysis. Acta Chirurgica Belgica, Bruxelas, v. 103, n. 5, p. 507-510, 2003.

WOLKOFF, A. G. Dicionário ilustrado de termos médicos e saúde. 1. ed. São Paulo: Rideel, 2005.

WYNGAARDEN, J. B.; SMITH, L. H. Cecil: tratado de medicina interna. 18. ed. Rio de Janeiro: Guanabara Koogan; 1990.
Recebido em 5 abr. 2006 / aprovado em 14 jul. 2006

\section{Para referenciar este texto}

BARBIERI, R. L. et al. Cisto epidermóide: relato de caso. ConScientiae Saúde, São Paulo, v. 5, p. 115-120, 2006. 